\title{
Quelles conceptions temporelles pour analyser l'activité ? Une proposition issue de recherches en ergonomie dans l'horticulture
}

What kind of temporal concepts to analyze work activity? A proposal from a research in ergonomics in horticulture production

\section{Valérie Zara-Meylan}

\section{OpenEdition}

Journals

Édition électronique

URL : http://journals.openedition.org/activites/2732

DOI : 10.4000/activites.2732

ISSN : $1765-2723$

Éditeur

ARPACT - Association Recherches et Pratiques sur les ACTivités

\section{Référence électronique}

Valérie Zara-Meylan, « Quelles conceptions temporelles pour analyser l'activité ? Une proposition issue de recherches en ergonomie dans l'horticulture », Activités [En ligne], 13-1 | 2016, mis en ligne le 15 avril 2016, consulté le 19 avril 2019. URL : http://journals.openedition.org/activites/2732 ; DOI : 10.4000/activites. 2732

Ce document a été généré automatiquement le 19 avril 2019

\section{(c) $(1)$}

Activités est mis à disposition selon les termes de la licence Creative Commons Attribution - Pas d'Utilisation Commerciale - Pas de Modification 4.0 International. 


\title{
Quelles conceptions temporelles pour analyser l'activité ? Une proposition issue de recherches en ergonomie dans l'horticulture
}

\author{
What kind of temporal concepts to analyze work activity? A proposal from a
} research in ergonomics in horticulture production

Valérie Zara-Meylan

\section{NOTE DE L'ÉDITEUR}

Article soumis le 11/09/2015, accepté le 05/02/2016

$1 \quad$ L'objectif de cet article est de présenter une catégorisation temporelle issue de plusieurs disciplines en sciences sociales, et opérationnalisée au cours d'une recherche en ergonomie pour analyser l'activité de travail en situation dynamique. Cette catégorisation a permis d'élaborer un positionnement théorique pour aborder l'activité en tant qu'agir temporel multimodal. Elle permet d'analyser les modalités de gestion de systèmes temporels complexes par des chefs de culture en horticulture, dans des conditions caractérisées par un enchevêtrement d'exigences multiples.

Pour cela, nous cherchons à constituer une approche qui reconnait plusieurs dimensions paradigmatiques aux temporalités humaines, au-delà du seul temps linéaire et chronique le plus couramment considéré. Nous puisons dans des recherches en sociologie, en philosophie du temps, et en sciences historiques pour distinguer quatre modalités temporelles opérantes pour les analyses. Le modèle ainsi produit est au cœur de notre thèse d'une gestion active de leur milieu temporel de travail par les travailleurs, ceux-ci déployant ces différentes modalités d'action sur les cadres temporels dans leur activité (Zara-Meylan, 2012a, 2013b). 
3 Dans cet article, nous examinons tout d'abord les enjeux de l'approche des temporalités pour l'ergonomie de l'activité (1.-), ainsi que les spécificités de ces questions dans le secteur horticole qui connait une période d'intensification du travail (2.-). Après avoir présenté la méthodologie déployée (3.-), nous exposons les résultats en deux parties, avec les quatre conceptions temporelles identifiées auprès des horticulteurs (4.-) puis des exemples de configurations qui combinent ces modalités temporelles dans leur activité (5.-). Nous terminons avec une discussion conclusive sur les apports et les perspectives de la notion d'agir temporel multimodal pour recherche et l'action (6.-).

\section{Approches du temps et des temporalités en ergonomie}

4 En considérant l'activité dans une historicité technique et sociale comme son objet central, l'ergonomie a toujours cherché à appréhender le travail dans sa dynamique. Avec plusieurs disciplines en sciences sociales traitant du travail, elle considère qu'il faut aborder le temps tel qu'il est vécu, avec des intensités et des qualités, des sauts et des ruptures qui ne peuvent se satisfaire d'un modèle simple et linéaire. En ergonomie, on cherche à analyser un travail - processus, et la représentation multiforme de son déroulement temporel que s'en constituent les travailleurs, avec l'expérience, pour agir sur les situations en tenant compte de leur complexité (Weill-Fassina, 1990). La focale est "l'activité ", à comprendre dans des dynamiques dont les contenus, les formes et les échelles sont diverses et entremêlées dans des dimensions individuelles, techniques, et sociétales (Molinié, Gaudart, \& Pueyo, 2012 ; Teiger, 1993, p. 87 ; Weill-Fassina \& Valot, 1998). Le concept d'activité en lui-même fait l'objet de recherches dans lesquelles les aspects temporels sont fortement présents (et la présente revue s'en fait en particulier l'écho). Citons sans exhaustivité celles portant sur les dimensions de développement de l'activité (Béguin \& Clot, 2004), ou encore sur son caractère évolutif dans un travail conjoint avec d'autres systèmes (Owen, 2007).

5 L'activité, telle qu'elle est entendue en ergonomie, considère qu'une incontournable relation complexe et récursive relie le travail à ces multiples dimensions temporelles. «Le travail engendre le temps qui engendre le travail... », pour reprendre Jean-Louis Le Moigne lors de son intervention introductive au congrès de la SELF ${ }^{1}$ intitulé Temps et Travail (1998). Autrement dit, l'activité participe à produire le temps dans lequel elle-même s'inscrit. Les recherches menées en situations dynamiques le montrent particulièrement (Cellier, De Keyser, \& Valot, 1996), en mettant en évidence une gestion temporelle complexe qui vise à influer sur les processus conduits, en étant étroitement reliée à une gestion des risques, donc d'un non encore survenu. Ces recherches montrent plus précisément en quoi certaines actions visent à influer sur un ensemble de dynamiques techniques et sociales des situations de travail dans différents empans temporels, en vue d'ouvertures de possibilités pour l'activité future (Pueyo, 1999, 2012).

6 Cependant, quels sont les fondements théoriques de nos approches du «temps », et de quels modèles disposons-nous pour orienter nos analyses? Nous convenons que le temps unifié de la mécanique newtonienne sur lequel est basé le temps de l'horloge ne peut suffire à approcher l'activité individuelle et collective, mais paradoxalement, en divisant le travail en petites parcelles juxtaposées dans nos chroniques d'activitéz ${ }^{2}$ nous postulons implicitement un Temps de référence unique, supposé pur et universel. Ce temps au 
singulier, dit ordinaire (Dubar, 2014), caractérisé par une fuite en avant uniforme et toujours égale, est ainsi posé comme repère premier.

7 Nous rencontrons un autre paradoxe lorsque nous cherchons à analyser d'autres temps, et en particulier le temps vécu dans l'activité, pourtant familier en ergonomie. Au-delà du Temps qui serait unique et des repères sociaux calendaires et horaires qui le traduisent, le travailleur intègre aussi d'autres guides pour agir. Outre son estimation subjective de ces horaires et des durées, les recherches mettent en évidence sa mobilisation de systèmes de référence variés, avec selon le cas: l'identification de la survenue d'évènements, de changements d'état de la situation ou du processus, la qualification d'un indice, ou encore la prise en compte d'articulations internes ou externes à l'entreprise. Cependant, on peut s'interroger sur l'interprétation qui en résulte dans les recherches, car en arrière-plan de ces modèles et pour nombre d'auteurs, la focale porte alors sur "les problèmes d'adaptation temporelle des opérateurs" (de Montmollin, 1997, p. 269) ${ }^{3}$, c'est-à-dire que ces repères deviennent aussi une référence pour l'analyste ergonome, qui qualifie alors de plus ou moins exacte leur appréciation par les travailleurs. Les anticipations et les estimations de ces derniers sont ainsi considérées comme possiblement décalées, voire erronées, par rapport à un horaire ou un moment calendaire, un évènement, un changement d'état de la situation ou du processus, un indice, ou encore une articulation interne ou externe. Et ces référentiels, identifiés comme porteurs d'une réalité objectivable, deviennent opposables au temps vécu supposément analysé, mais considéré comme devant identifier et se plier à ces temps externes qui font foi.

Ne sommes-nous pas ainsi prisonniers de modèles analytiques et d'un ancrage dans les sciences positives dont nous dénonçons par ailleurs les limites?

Ces questions s'imposent d'autant plus vivement aujourd'hui que des formes multiples d'intensification du travail et des mouvements de rationalisation des systèmes de production supposés accroitre leur performance économique sont observés (Askenazy, Cartron, de Coninck, \& Gollac, 2006). Comme cela avait été analysé en écologie temporelle :

«Une compétition généralisée pousse aux accélérations, ce qui ne va pas sans inconvénients et malaises, sans menaces et dangers. L'urgence devient un impératif quotidien, dont les effets ne s'accordent pas forcément avec les objectifs poursuivis » (Grossin, 1998, p. 3).

10 Effectivement, des recherches insistent sur la nécessité d'associer aux approches de l'activité en situation des approches diachroniques, dans différentes dimensions temporelles pour caractériser le travail et ses évolutions (Volkoff, 2012). Comme cela est aussi souligné en sociologie, il est l'important d'associer l'analyse de dynamiques sociohistoriques et de celles présentes au cœur du travail (Rolle, 2014). Pour aborder le présent des activités humaines, il faut chercher à comprendre ce qui constitue le milieu dans lequel les individus et les collectifs évoluent (Michon, 2014). Pour cela, ce ne sont pas des notions de vitesse ou de lenteur qui sont les plus déterminantes, mais l'ensemble des dynamiques de l'activité et «leurs manières spécifiques de fluer » (idem, p. 51-53).

11 Des analyses ergonomiques s'attachent à détailler ces dynamiques, dans des dimensions de court et long termes, en examinant les combinaisons d'enjeux et de contraintes relatifs aux individus, aux collectifs et au système de travail, compte tenu de leurs évolutions (Molinié, Gaudart, \& Pueyo, 2012). Les travailleurs peuvent se trouver aux prises avec des écheveaux temporels particulièrement emmêlés, dans des situations qui nécessitent 
d'autant plus d'attention qu'elles sont reliées à des effets disparates et souvent négatifs sur la santé (Molinié \& Pueyo, 2012 ; Volkoff, 2008), et qu'elles peuvent aussi déboucher sur une fragilisation des collectifs et de la production elle-même (Cau-Bareille, 2012; Zara-Meylan, 2012b). Ces situations appellent de nouvelles approches, mobilisant différentes échelles de temps, mais aussi d'autres modalités de complexité temporelle des situations.

\section{Une période d'intensification du travail dans l'horticulture}

12 Ces questions revêtent un intérêt particulier dans différents secteurs, dont celui sur lequel porte cet article, l'horticulture. Pour répondre à une compétition économique renforcée, les exigences de réactivité, de flexibilité et de polyvalence sont de plus en plus valorisées au sein des entreprises. Des évolutions des systèmes de production censées soutenir ces objectifs ont été engagées, avec un repositionnement de la gamme de plantes proposées, une diversification des variétés, une mécanisation des équipements, ainsi qu'une recherche de rationalisation accompagnée de l'implantation d'outils de gestion (Pueyo \& Zara-Meylan, 2012). Ces changements sont appuyés sur des modes de contrôle et d'évaluation rigide du travail dominés par le temps de l'horloge, en tant que temps linéarisé porteur d'ordre. Cependant, ils ne semblent pas permettre de stabiliser les processus de production, et ils n'apportent pas non plus les bénéfices escomptés en termes de qualité. Ils semblent au contraire compliquer les conditions temporelles du travail, avec des sollicitations physiques persistantes malgré la mécanisation, ce qui amène les dirigeants à interroger (voire à remettre en cause) les compétences de métier de leurs salariés, et en particulier du chef de culture responsable de l'équipe de production.

13 Pour comprendre ces conditions temporelles et leurs effets, nous examinons l'activité de ces chefs de culture, effectivement identifiés dans le cadre de nos recherches ${ }^{4}$ pour leur rôle clé dans l'obtention des objectifs de production. Ce métier nécessite des savoirs professionnels qui vont bien au-delà des connaissances en « conduite de culture » spécifiées dans les fiches métier (ANEFA, 2006a, 2006b). Bien qu'indispensables pour mener les itinéraires techniques des plantes dont ils ont la charge, elles sont loin de suffire dans la réalité de leur travail.

14 Précisons tout d'abord que, contrairement aux représentations courantes selon lesquelles la saisonnalité et les spécificités biologiques des végétaux détermineraient les exigences temporelles du travail dans ce secteur, les caractéristiques et besoins des plantes ne sont pas complètement prédéfinis et immuables. Ils dépendent d'une part de la recherche variétale (historiquement très développée dans le secteur) qui en fait évoluer les caractéristiques, et d'autre part de choix de l'entreprise en matière de conditions techniques (équipements, abris, exposition des parcelles, gestion climatique, etc.), qui peuvent déplacer certains déterminants biologiques (Bron, Duclaud, \& Toussaint, 2004).

De plus, selon le positionnement qualité de l'entreprise, les mêmes espèces de plantes peuvent être vendues à différents moments de l'année et en étant plus ou moins hautes, compactes, feuillues, en boutons, etc. Enfin, le suivi et les soins à apporter aux végétaux ainsi que les cycles de production dépendent largement aussi de l'organisation de la production dans ses relations avec les autres services (commercial, expéditions). 
16 Ainsi, chaque chef de culture doit plus largement assurer un travail d'articulation, en tenant compte d'une diversité de composantes techniques et organisationnelles qu'ils doivent identifier dans leurs situations (Gotteland, Zara-Meylan, \& Pueyo, à paraitre). Ce travail d'articulation, et en particulier dans sa dimension de gestion temporelle, relève de savoirs pour beaucoup élaborés au fil de leur expérience, mais ils sont peu formalisés dans le métier.

17 En s'appuyant sur des concepts développés en écologie temporelle (Grossin, 1996), une première phase de nos recherches a permis de proposer de catégoriser les exigences du travail des chefs de culture, en termes de "cadres temporels " plus ou moins rigides qu'ils gèrent dans leur «milieu temporel » (Zara-Meylan, 2012a, 2013b). Ainsi, dans chaque situation, on peut repérer des cadres temporels relatifs au planning de culture qui fixe les grandes orientations de la production et le positionnement de marché (variétés, itinéraires techniques et saisonnalité), aux moyens techniques associés (équipements, abris, exposition des parcelles, gestion climatique, etc.), à l'organisation d'ensemble du travail (modes de prescription et de contrôle, articulation production et expéditions), et à des exigences imposées plus localement (affectations, urgences, etc.).

Les chefs de culture prennent aussi en compte différents processus, qui constituent des ensembles distincts de "phénomènes organisés dans le temps " (Mendez, Bidart, Brochier, Correia, Garnier, Gilson et al., 2010), à conduire en tenant compte de leurs influences mutuelles. Outre les processus de croissance des plantes tels que classiquement définis en ergonomie en situation dynamique (Cellier et al., 1996), nous avons identifié d'autres processus suivis par les chefs de culture: les conditions biosphériques des différents espaces de culture, et le processus de travail des équipes.

Chaque chef de culture conduit ainsi ces processus en prenant en compte ces cadres temporels à la fois contraintes et ressources, car ils délimitent son activité et ils sont aussi susceptibles de la soutenir et de la structurer, dans des combinaisons spécifiques. Examinons dans cet article les conceptions par lesquelles ils appréhendent et s'emparent de ces cadres temporels dans leur milieu temporel.

\section{Méthodologie et dispositif de recherches}

Les analyses présentées sont issues de travaux menés par une équipe d'ergonomes du Gis CREAPT $^{5}$ dans une perspective de recherche et d'action, au cours de trois projets en partenariat ${ }^{6}$. Nos recherches ont plus particulièrement été réalisées sur neuf sites de six entreprises (Zara-Meylan, 2012a) : dans deux entreprises horticoles (appelées ici IS et MA) produisant sous serre des plantes en pot fleuries (bégonias, cyclamens, azalées, poinsettias, etc.) et quatre pépinières produisant des arbustes de haie et autres plantes d'extérieur en hors-sol (photinias, eleagnus, escallonias, lierres, etc.) chez LO, PE, VA site $\mathrm{A}$, et $\mathrm{BE}$, ainsi que des arbres d'ornement en pleine terre (érables, hêtres, pins, ormes, etc.) chez PE et VA site B.

Dans chaque entreprise, ces recherches ont été appuyées sur une intervention menée avec nos partenaires projets, sur une période de deux à six mois. Après une phase d'entretiens avec les dirigeants, puis la consultation de documents sur l'organisation et ses évolutions récentes, nous avons mené des entretiens semi-dirigés sur les relations qualité-santé-travail avec des salariés de tout niveau hiérarchique, ainsi que des 
observations du travail des équipes et du chef de culture sur les neuf sites, durant une à treize journées.

Pour aborder plus spécifiquement les conditions temporelles de leur activité et leurs conceptions temporelles, les analyses ont été resserrées et systématisées auprès de cinq chefs de culture ayant 7 à 35 ans d'ancienneté (chez MA, PE, deux sites de VA, et BE). Chacun a en charge la production sur son site et l'organisation du travail d'équipes de deux à six ouvriers permanents, un à deux apprentis, et jusqu'à trois saisonniers. Des entretiens semi-dirigés spécifiques ont été menés auprès d'eux ( $1 \mathrm{~h} 15 \mathrm{à} 2 \mathrm{~h}$ ), pour identifier les différents cadres temporels de leur activité et élucider les modalités de leur mobilisation. Une grille a été spécifiquement bâtie dans cet objectif, et discutée et testée avec les partenaires projets MSA Languedoc (cf. note précédente). Elle comporte six séries de questions ouvertes qui concernent:

- la conduite saisonnière de la production,

- le travail d'organisation,

- les tâches critiques en termes de risques,

- les journées qui vont bien et les situations redoutées,

- une journée ou une situation récente marquante,

- et enfin un retour sur des situations redoutées.

Les entretiens ont été retranscrits, et les premières analyses présentées et discutées en premier lieu avec les chefs de culture concernés ( $1 \mathrm{~h}$ à $1 \mathrm{~h} 45$ avec chacun, au sujet de son propre entretien). Les analyses de leur gestion multimodale de leur milieu temporel ont ensuite été complétées avec les apports d'observations systématiques de l'activité, réalisées auprès des cinq chefs de culture durant une à quatre journées (durées de $7 \mathrm{~h} 30$ à 9 h30 chacune).

Il faut souligner que dans une perspective méthodologique familière à l'ergonomie, les interprétations des entretiens comme celles des observations (et des verbalisations associées) ont été réalisées en considérant les travailleurs comme coproducteurs de l'analyse de l'activité (Teiger, 1993), et comme producteurs de sens (Demazière \& Dubar, 2004). C'est-à-dire que nous n'avons pas préétabli de catégories que nous aurions cherché à retrouver dans les propos des travailleurs. L'ensemble des données ainsi que les commentaires des travailleurs ont au contraire été pris en compte, pour faire émerger une diversité de liens entre les faits et une variété de logiques, et pour rechercher des critères pour des catégorisations pertinentes (Volkoff, 2005).

C'est cette démarche qui nous a amenée à mobiliser des apports de la philosophie et des sciences historiques pour distinguer tout d'abord trois conceptions temporelles puis une quatrième (cf. partie suivante), cette combinaison s'avérant fructueuse dans son opérationnalisation lors de l'analyse des entretiens, puis des suivis d'activité. Cette démarche a aussi permis de dégager des configurations temporelles spécifiques dont les chefs de culture identifient les composantes et qu'ils structurent en combinant ces différentes conceptions du temps. Nous présentons ici en particulier deux « configurations redoutées $»^{7}$ (Zara-Meylan, 2013a), issues d'un entretien et d'une des journées d'observation chez BE (cf. 5.). 


\section{Différentes conceptions temporelles pour analyser (le milieu temporel de) l'activité}

Pour analyser les modalités de gestion de leur milieu temporel par les chefs de culture, nous suivons les apports de la philosophie qui, selon Dubar (2008), a montré la possibilité de penser la coexistence, dans une même situation, de plusieurs "niveaux et formes de temporalisation ", c'est-à-dire plusieurs "manières de définir, penser, vivre le temps» (p.5). Cette démarche permet de dépasser les apories inhérentes aux approches d'un temps supposé unifié, en considérant que différents paradigmes peuvent cohabiter dans une même situation.

Pour ce faire, nous considérons la coexistence de trois grandes familles de lecture du temps telles qu'analysées par Le Moigne (1997), en les complétant par une quatrième issue des recherches en sciences historiques.

\subsection{Le temps poussé par le passé (Temps 1)}

\subsubsection{Quand le passé contient toutes les données pour le futur}

Le paradigme du temps « poussé par le passé » est selon Le Moigne (1997), celui d'un temps directement calqué et bâti à l'image des cycles cosmiques, dans le sillage d'une tradition ancrée sur le positivisme et d'une certaine conception de la physique. C'est le temps d'un monde dans lequel l'état suivant est toujours prévisible, qu'il soit considéré comme régi par les lois de la dynamique newtonienne (entretenu alors dans la stabilité) ou par celles de la thermodynamique (une instabilité évoluant inéluctablement vers des états prévisibles). Cette acception du temps, que Le Moigne qualifie d'entropique, est selon lui intrinsèquement déterministe, car en examinant le contenu du passé, y compris de son désordre, et si notre esprit était capable d'une telle évaluation, on pourrait prédire les évènements et l'état de désordre futurs. Autrement dit, le passé contient toutes les données pour le futur.

L'introduction des concepts de complexité du présent et d'incertitude dans l'appréciation du futur n'a pas forcément bouleversé cette conception du temps (Zarifian, 2001). Pour analyser une réalité complexe et ses évolutions incertaines, des outils mathématiques sophistiqués ont été développés pour modéliser des situations et décrire des tendances, par exemple concernant l'évolution des marchés financiers, les projections d'un plan, les décisions (théories et graphes de décision) ou pour évaluer des probabilités d'occurrence de certains évènements, comme c'est le cas en matière d'évaluation de risques professionnels, épidémiologiques, technologiques ou environnementaux. Ce temps est celui des approches probabilistes et de la "société du risque » (Beck, 2001). Les évènements survenus dans les mois ou années passés constituent une route qui a été suivie et dont le tracé projectif peut être transformé en risque pour l'à-venir. De ce point de vue, le futur peut relever d'une estimation scientifique, à partir d'un passé et d'un présent qui constituent une base mesurable, des données de la situation; et l'action humaine ellemême peut être intégrée dans cette évaluation de l'avenir.

Ce temps est en particulier celui de l'horloge, fruit de la domestication symbolique de l'espace et de l'écoulement temporel qui a abouti à concevoir un réseau de symboles métriques ainsi que calendaires et horaires (Leroi-Gourhan, 1973, pp. 140-141). Sa vertu a 
été de constituer une base opératoire commune à partir de laquelle sont organisés notre vie, nos repères et nos synchronisations sociales. Ayant été adopté comme le Temps absolu et universel, le temps chronique, réputé neutre et stable, peut faire référence pour situer les évènements du vivant. Étant objectivé et mesurable, il fait foi, autorise la figuration spatiale, la métaphore énergétique et le calcul mathématique.

Dans le domaine du travail, mesure chronométrique et mesure mécanique ont ainsi été associées pour des théories du rendement de la «machine humaine» et de la valeur économique du travail en termes de "force déployée » à une certaine vitesse, par unité de temps (Vatin, 2014). Cette mesure d'un travail abstrait qui en élimine tout contenu qualitatif est connue pour avoir été en particulier répandue au service des organisations tayloriennes. Ses limites et ses conséquences ont été abondamment analysées et dénoncées par différentes disciplines traitant du travail. Cependant, les représentations courantes en sont toujours imprégnées, avec par exemple les dispositifs de supervision en termes de temps de travaux, cadences, ou durées d'«activités " selon des catégories préétablies, qui se sont répandus dans de nombreux secteurs professionnels (Amossé, Cartron, Castell, Célérier, Pueyo, Wolff, \& Zara-Meylan, 2014) et en particulier en horticulture (Pueyo \& Zara-Meylan, 2012). Nombre de nos systèmes sont plus largement fondés sur une "formidable autodiscipline du temps", qui nous enferme dans "une visée de maitrise du monde" (Zarifian, 2001, p. 36). Ils nous imposent une "société synchrone intégrale ", régie par un temps bouclé à l'avance (Chesneaux, 1983). C'est ce que traduisent de façon particulièrement éloquente l'informatisation et les outils de pilotage dits en temps réel dans les entreprises, car " l'activité de l'entreprise et des services est effectivement "saisie" à vif, mais selon un réel factice et codifié parce que construit à partir des seuls facteurs programmés a priori à l'intention de l'ordinateur - donc en excluant tout imprévu» (idem, p. 37).

Certaines limites de cette conception du temps lui sont aussi intrinsèques. Plusieurs de ses apories ont été relevées par des philosophes et des physiciens depuis longtemps (Dubar, 2008, 2014), et nombre d'entre elles sont liées à la réalité qui lui est attribuée. La métaphore du temps qui coule, inéluctablement et continument, comme le ferait un fleuve, amène en particulier des questions. Car dans ce cas, dans quoi ce temps coule-t-il ? Quel en est le lit? Que sont ses berges? Considérer l'écoulement continu du temps postule «l'existence d'une réalité intemporelle dans laquelle passerait le temps» (Klein, 2003, p. 25). Cela présuppose donc qu'il y aurait de l'a temporel, ce qui est impossible à imaginer.

De plus, de nombreuses représentations spatiales (linéaires, circulaires, en spirale...) constituent « autant de rappels d'un grand principe théorique, celui de la non-représentatibilité directe du temps ", comme l'affirme Chesneaux (2004, p. 114). Ce temps par lequel nous cherchons à nous rendre "maîtres des évènements" (Bergson, 1959) postule que chaque seconde vaut la précédente. Il nous cantonne ainsi à une " une méthode cinématographique "(p.228) qui ne nous permet de saisir de la réalité mouvante que des séries d'instantanés. Le temps déroulé en espace laisse de côté «l'intensité $d u$ vécu » qui appelle plutôt des « qualités » de temps. Il laisse échapper un autre aspect du réel, de l'évolution et de la transformation des choses qui relève de "l'intérieur du devenir». Il nous fait perdre de vue ce que le temps est avant tout, « une durée vraie » qui relève d'une « création » (idem) humaine, une durée à relier aux phénomènes du vivant. 


\subsubsection{Le temps poussé par le passé dans les systèmes de travail en horticulture} passé est pourtant incontournable, comme nous l'avons souligné, dans la mesure où il constitue un socle de repères communs fondamentaux pour les organisations. En horticulture et en pépinière, il permet un premier niveau d'éclairage des conditions temporelles du travail. Dans l'encadré 1 ci-dessous, nous en donnons des éléments issus des entretiens exploratoires menés dans les entreprises.

Encadré 1 : Conception d'un temps « poussé par le passé » chez les chefs de culture (Temps 1). Box 1: Horticulture managers' conception of time "pushed by the past" (Time 1)

Dans toutes les entreprises, un planning de culture fixe l'échelonnement saisonnier* de la production de façon plus ou moins détaillée, avec les semaines de mise en culture des lots, et les périodes de ventes envisagées. Les chefs de culture les croisent avec le calendrier, et en particulier les fêtes traditionnelles car par exemple, «les bégonias, c'est pour la fête des mères, et après on n'en vend plus " (Horticulture IS). Ces repères sont établis d'année en année sur le calendrier et dans le système informatique.

L'organisation d'ensemble fixe les horaires de travail au fil des jours et des semaines (annualisation des horaires ou pas, heures d'été, etc.), les permanences de week-end, et aussi les périodes sans congés (samedi avant la fête des mères, ou encore la semaine de Noël, chez IS et MA). Elle fixe les horaires de livraison, les jours de marché, et les rendezvous avec des acteurs internes ou externes à l'entreprise.

Des automates répartis sur différentes zones de chaque entreprise commandent l'arrosage en séquence des parcelles, la pression d'eau disponible étant limitée. Leurs sélecteurs, gradués en minutes (ou $5 \mathbf{~ m n}$ ), nécessitent des calculs en h-mn, et les chefs de culture prévoient parfois des "marges de sécurité de $5 \mathbf{m n}$ " (Pépinière LO) entre certaines plages. Chaque déclenchement (ou arrêt) de l'arrosage peut devenir une butée temporelle (ou un déclencheur) pour certains travaux sur la parcelle.

Dans toutes les entreprises, de nombreuses consignes et règles sont énoncées en termes horaires. Citons l'application des pesticides, avec les intervalles de traitement et les délais de réentrée après application dans une serre. Autre exemple, celui des cadences et des quotas instaurés pour certains travaux avec la modernisation des équipements et l'achat des machines à rempoter. Des contrôles et des évaluations quantifient la performance en nombre d'unités rempotées, tuteurées, taillées, traitées ou dépotées, par heure, jour, semaine ou saison.

Certains chefs de culture établissent des plannings prévisionnels de travail, quotidiens ou hebdomadaires, pour prévoir la réalisation des travaux en fonction des outils, et des effectifs. Certains tiennent des agendas, et ils y retranscrivent jour après jour les principales opérations réalisées, dans l'objectif de constituer des traces du travail passé et de la maturité des lots, éventuellement mobilisables pour les années suivantes.

* EN gRAS dans les quatre encadrés : des marqueurs pour repérer la conception temporelle décrite.

Ce temps poussé par le passé fixe des repères fondés sur le calendrier et l'horloge, et il permet la commande des objets techniques, et les synchronisations sociales. Cependant, il 
admet mal les évolutions, la variabilité des situations aux exigences enchevêtrées et l'irrégularité des processus à gérer. Ce temps toujours égal ne traduit pas les notions d'intensité, les changements de tempo et la réactivité nécessaire dans les situations d'urgence.

Ainsi, les horaires de travail peuvent être en décalage avec la durée du jour certains jours d'hiver, et imposer un début de matinée dans la pénombre, avec la crainte de laisser passer des Escallonia un peu jaunis dans les premières préparations. Autre exemple, la programmation en tranches horaires de l'arrosage nécessite des compromis car les plantes rassemblées sur les parcelles n'ont pas toujours des besoins complètement homogènes. Elle nécessite aussi des priorisations lorsqu'il faut arroser d'urgence un lot en souffrance sans faire tomber la pression d'eau. De plus, chaque modification nécessite des déplacements rapides dans la pépinière, pour revoir la programmation de plusieurs automates dont les tableaux de commande, souvent de générations différentes, n'ont pas la même logique (sélecteurs par voie ou menu déroulant, réglage à la minute ou par tranches horaires, etc.). Pour absorber les éventuels décalages d'horloges ou les problèmes de calculs qui amèneraient des chutes de la pression d'eau, les chefs de culture insèrent de courtes plages de pause dans ce séquencement rigide.

Citons encore les cadences de travail, établies en fonction du diamètre des pots, mais qui ne tiennent pas compte de la diversité des plantes, de leur état, et qui ignorent les conditions climatiques. Pourtant, les chefs de culture savent que des plantes très larges, lourdes, plus fragiles, piquantes, ou mouillées sont plus difficiles à manipuler. Il peut en résulter une accumulation de fatigue, qui rend encore plus difficile l'atteinte des objectifs de quantité et de qualité, ainsi que des douleurs qui pourront perdurer plusieurs jours, ou même s'installer. Les durées de travaux standardisées ne comprennent pas non plus les nombreux soins (surveillance, arrosage, tuteurs...), pourtant indispensables à la qualité, et encore moins les rattrapages face aux aléas, par exemple si le vent fait chuter certaines plantes.

Les plannings de travail permettent de poser d'indispensables repères pour les travaux envisagés, le matériel, et les affectations, mais ils sont très vite obsolètes, et ils ne sont que rarement directement applicables. À l'échelle plus large des plannings de culture, les demandes des clients et les choix du service commercial étant variés et peu prévisibles, les agendas ne semblent même plus constituer un support de référence d'une année à l'autre (Horticulture IS, Pépinière BE). À tel point que certains disent avoir renoncé à tout plan formel :

«le planning, à un moment donné, on a arrêté d'en faire parce qu'il y a tout le temps quelque chose qui vient se greffer au milieu et qui empêche d'avancer [...]» (Pépinière PE).

Pourtant, des repères chroniques et en particulier calendaires restent indispensables et ce même chef de culture précisait juste après : «c'est dans la tête [...] Vous savez, le temps qui passe... Malgré tout, on a quelque expérience ». Il faisait ainsi état d'une forme de mobilisation de son expérience passée, pour associer au calendrier d'autres formes de repères, plus souples et plus pertinents dans son activité.

Bien qu'il fixe d'indispensables repères structurants, ce temps poussé par le passé, que nous nommerons aussi pour plus de commodité temps de l'horloge et du calendrier, doit être complété par d'autres approches pour comprendre l'activité des chefs de culture. 


\subsection{Le temps tiré par le temps à venir (Temps 2)}

\subsubsection{L'orientation vers un ordre temporel} propriétés biologiques et chimiques intrinsèques aux plantes dans leur environnement naturel et saisonnier, indépendamment de toute activité humaine. Des recherches en ethnologie montrent que les «temps agricoles » ne peuvent être appréhendés en séparant strictement, d'une part l'étude par les sciences de la nature et des conditions bioclimatiques, et d'autre part celle des sciences humaines concernant les formes de domestication de cette nature. Par exemple lorsqu'il s'agit de déterminer la date de début des vendanges dans une coopérative agricole (Shippers, 1995), la maturité des vignes est appréciée en intégrant des critères sociaux et pratiques liés aux possibilités de se mobiliser à un moment donné autour des vendanges. envisagée pour un lot, qui peut étroitement dépendre des périodes promotionnelles et de l'impression des plaquettes publicitaires associées, programmées plusieurs mois auparavant par une jardinerie cliente. Ainsi, à partir de la prévision de la période de vente attendue pour tel ou tel lot de plantes, pourront être anticipés et ajustés des actions 
sur les cultures, puis des moments de mobilisation autour de la mise au disponible ${ }^{8}$ et de la vente. Il faut compter avec cet ordre qui pourra s'imposer et être en cohérence, ou pas, avec le temps poussé par le passé (temps 1) cristallisé dans le calendrier de production.

Encadré 2 : Conception d'un temps « tiré par le futur » chez les chefs de culture (Temps 2). Box 2: Horticulture managers' conception of time "pulled by the future" (Time 2)

Les processus de croissance des végétaux sont pré déterminés par les caractéristiques botaniques (dans le sens d'une inscription génotypique) des espèces et de spécificités variétales. Ils sont en arrière-plan des itinéraires techniques qui prévoient leurs dynamiques, leurs besoins à chaque stade d'évolution, et le travail à réaliser. À partir du suivi et d'un diagnostic à un moment donné, ces connaissances permettent des déductions sur l'état futur d'un lot.

On peut citer l'analyse réalisée avec un chef de culture (Horticulture IS) à propos de lots de cyclamens qu'il suit en estimant ses évolutions futures : beau volume ou au contraire montée en fleurs trop précoce, plantes trop hautes, risques de flétrissement, piqures de ravageurs avec dégâts futurs irréversibles, etc. Autre exemple, la prédiction formulée par un autre chef de culture (Pépinière $\mathrm{BE}$ ) devant l'état des troènes qu'il estime asséchés : «ils vont perdre leurs feuilles ", et ce, quelles que soient les actions d'arrosage qu'il peut engager dans l'immédiat. C'est aussi le temps du niveau de qualité auquel il faut s'attendre, par exemple pour des lavandes: "on ne les a pas taillées, on ne va pas pouvoir les vendre" (Pépinière LO).

Certaines évolutions du processus biosphère peuvent être envisagées au fil des saisons, et aussi plus localement. C'est le cas de l'inéluctable développement des herbes qui pointent dans les pots, des prochaines atteintes de thrips par une contamination que le champ de tournesols voisin laisse présager, du retour de la pluie annoncé par la météo et confirmé par la masse nuageuse qui approche.

Le processus de travail peut aussi être envisagé sur ce mode, par exemple du fait de la conduite technique choisie et du positionnement qualité : «si elles (les lavandes Papillon) ne sont pas vendues, il faudra les tailler " (Pépinière LO), ou d'incontournables relations spatiotemporelles : «pour libérer de la place, on est obligé de regrouper les plantes » (Pépinière $\mathrm{BE}$ ).

Les exemples rapportés dans l'encadré ci-dessus montrent que l'ordre du temps concerne le processus de croissance des plantes dont il régit et permet de prédire la croissance. Il permet aussi d'envisager les évolutions saisonnières de la biosphère, ainsi que le déroulement du processus de travail d'une équipe autour de travaux (compte tenu des effectifs, compétences, outils, espaces, état de santé, et de rationalités locales). Cette approche du temps est souvent mobilisée en rapportant au calendrier les évolutions envisagées, donc en la croisant avec la conception du temps 1 décrite ci-avant. Notons également que l'expression « on ne va pas pouvoir les vendre » au sujet des lavandes dans la pépinière LO renvoie aussi au temps 3 des « possibles » qui sera abordé ci-dessous (cf. ).

Ce temps (2) est exprimé en termes d'impératifs nécessaires au déroulement des opérations à réaliser sur un lot " il faut ", " il sera nécessaire ", " on est obligé de », ou encore du stade de développement de la plante estimé dans une période future avec "ils vont grandir », "perdre leurs feuilles », etc., du volume du feuillage et de l'avancée de la 
floraison attendus étant données les conditions climatiques actuelles et les soins envisagés.

\subsection{Le temps construit par le temps présent et ouvrant l'avenir (Temps 3)}

\subsubsection{La création temporelle dans les situations} dégage de nos représentations, et "l'attention vigilante» de chacun est orientée vers l'ensemble des potentialités ouvertes dans l'avenir. Il précise: «Ce n'est pas la représentation, toujours réitérable, d'un moment postérieur au moment actuel qui ouvre l'avenir, mais l'orientation vers une potentialité qui prend valeur de but ou de repère » (p. 189). Ainsi, le but considéré dans la dynamique des activités humaines n'est pas l'accomplissement direct de tel ou tel état, évènement ou action, mais il se rapporte à la potentialité ellemême, à la possibilité que cet accomplissement se produise. monde entretenu dans la stabilité ou voué à une dégradation progressive jusqu'à un état final inerte. Ces conceptions du monde étant «négatrices du temps » (p. 231), il propose de considérer au contraire "les temps comme l'expression des vies» (id., p. 232). Les temps pertinents sont ceux des êtres individuels comme des milieux, des temps composites qu'il faut aborder comme l'expression de phénomènes qui contribueraient à relier la matière à la vie, et donc qui résultent de la vie elle-même.

On peut rapprocher ces réflexions des approches pragmatiques de l'action qui insistent sur la créativité intégrée dans l'agir humain. L'agir dans le travail ne peut être considéré dans de seules dimensions rationnelles et normatives comme la poursuite de seules fins préconçues qui seraient ensuite déclinées dans l'action, mais aussi dans une dimension de "créativité située ", pour reprendre le sociologue H. Joas, cette créativité s'exprimant 
dans chaque situation en termes recherche d'ouverture de "possibilités pratiques» (Joas, 2004, p. 143).

\subsubsection{Le temps construit des ouvertures d'avenir dans le travail horticole}

54 C'est le temps auquel il est fait référence en horticulture dans toutes les situations où les travailleurs s'expriment en termes de possibles, tenant compte d'un futur de situations où incertitude et variabilités sont inévitables. Ainsi, dans la pépinière $\mathrm{BE}$ le responsable de production explique en quoi ses décisions d'organisation ont pour effet d'agir sur le déroulement futur de la production et les conditions futures de son suivi, et aussi sur les possibilités d'agir qui seront disponibles (Encadré 3).

Ce rapport au temps ouvrant des possibles et produisant des impossibles est celui des « on pense (ou on est sûr de) pouvoir ", "on peut », " on pourra »... ou "pas». Les actions de construction de possibles peuvent relever d'un choix « permettant de », « de manière à », ou « amenant $\grave{a}$ », etc. Comme pour les précédents, cette conception temporelle est mobilisée en association étroite avec les autres, en particulier avec des références au calendrier ( temps 1) et la prédiction de l'évolution des lots (temps 2).

Encadré 3 : Conception d'un temps « construit par le temps présent » chez les chefs de culture (Temps 3).

Box 3 : Horticulture managers' conception of time "built by the present" (Time 3)

Les chefs de culture cherchent, par leurs actions, à influer sur le déroulement des situations, par exemple à l'échelle de la semaine à venir : « on concentre les livraisons (sur les premiers jours de la semaine) et ça permet d'organiser la semaine en plusieurs phases, d'être sûr de pouvoir se consacrer aussi à la production. » (BE). Ils évoquent en particulier les possibles et des impossibles qu'ils envisagent dans la dynamique des situations : "Souvent, le début de semaine, on pense pouvoir faire le travail. Mardi par exemple, on pense qu'il n'y a pas trop de commandes. On pense pouvoir se consacrer dès le départ au travail, au travail de production. Et puis, grosse commande, et elle nous emmène là où des fois, le lundi, il nous arrive de faire des heures supp le soir. [...] Donc on a des équipes assez souples et voilà, s'il faut rester le lundi soir plus tard, on le fait de manière à assurer les ventes, de ne pas les louper» (BE)

La construction du temps s'apparente parfois à un pari, tant l'incertitude est forte. Ainsi, alors qu'il hésite au moment de jeter un lot de plantes dégradées, ce même chef de culture commente : "Jeter, c'est un pari. Leur donner une chance, on les laisse encore. Les jeter, ça fait mal au cœur. Mais en même temps, c'est le meilleur pari. À court terme, on perd. Mais on ne reporte pas la situation ". À ce moment, garder ou jeter des plantes qui auraient encore " une chance » de reprendre relève d' " un pari » difficile, car cette alternative correspond à deux avenirs possibles, chacun étant à considérer dans des horizons proches et plus lointains.

Dans cet exemple, le chef de culture peut s'engager, soit vers un suivi coûteux à court terme ouvrant des possibles pour ce lot à plus long terme, soit vers la fermeture de ces possibles avec une perte immédiate (car on jette le lot), mais la certitude de " ne pas reporter la situation " c'est-à-dire de ne plus du tout être tenu de suivre un lot dégradé. Ce dernier choix constitue pour lui le pari par lequel il cherche l'ouverture d'un nouveau possible pour suivre de toutes les autres cultures. 
56

que dans ces situations dynamiques, l'ouverture de possibles ne consiste pas forcément en une réduction de l'incertitude. En utilisant le terme de pari un chef de culture fait référence à une notion de hasard, heureux ou malheureux, portant à la fois les idées d'incertitude et de risques (Pueyo, 2012). Pour lui à ce moment, le pari est une action dans l'incertitude, traduisant une stratégie d'ouverture d'une chance potentielle (hasard heureux) à saisir dans l'avenir (Morin, 2005).

\subsection{Le temps uchronique des alternatives passées (Temps 4)}

Les analyses réalisées auprès des chefs de culture nous ont amenés à compléter la proposition de Le Moigne en mobilisant un quatrième paradigme temporel, puisé dans des recherches en sciences historiques. Il s'agit de prendre en compte la conception temporelle sur laquelle les chefs de culture s'appuient quand ils reviennent sur un moment du passé et sur les perspectives et les possibles qui s'offraient alors, en identifiant ce moment à partir du présent. Nous qualifions cette conception d'uchronique, en empruntant ce vocable à un genre littéraire, l'uchronie.

\subsubsection{L'uchronie, pour revenir sur les bifurcations du passé}

En littérature, l'uchronie est une histoire refaite en pensée telle qu'elle aurait pu être et qu'elle n'a pas été. Selon Renouvier $(1876)^{9}$, à qui on attribue l'invention du terme, l'auteur d'une uchronie écrit l'histoire, non telle qu'elle fut, mais telle qu'elle aurait pu être, à ce qu'il croit, et ce à partir de la modification d'un événement du passé ou du changement de son issue. On trouve de tels ressorts dans des récits déjà anciens, comme dans des ouvrages plus récents. Citons l'un des plus populaires de ce genre, « Le maître du haut château ", de Dick (1970), qui décrit un monde contemporain alternatif en imaginant les conséquences qu'aurait eues une autre issue de la Seconde Guerre mondiale ${ }^{10}$. Ainsi, " en suspendant la variable temporelle - celle de l'histoire réelle (si tant est que celle-ci existe en soi) - il s'agit de regarder ce que nous aurions pu devenir si d'autres options que celles qui ont configuré notre devenir avaient été développées » (Lallement \& Ramos, 2010, §5).

Dans ce sens ${ }^{11}$, qui est celui adopté dans notre recherche, l'uchronie est à rapprocher de la démarche historique, pour laquelle il s'agit de pointer les moments de bifurcations qui auraient pu donner lieu à d'autres trajectoires, à une autre histoire :

«Il s'agit là de ne pas s'en tenir aux seuls résultats qui, apparemment, nous sont parvenus de différents moments passés, mais de faire ressortir le présent complexe et incertain de chacun d'eux, les héritages et possibilités qui s'offrent et s'imposent aux acteurs d'alors. Et surtout de réintroduire le plus possible ces derniers dans leur plénitude» (Hatzfeld, 2008, p. 5).

a notion d'uchronie, telle que nous l'entendons, intègre ces dimensions de complexité et d'incertitude couramment arasées dans les références traditionnelles au passé. Elle peut renvoyer aux échecs, aux potentialités inaccomplies, à ce qui dans le passé est resté en « projet » (Ricœur, cité par Chesneaux, 1996, p. 275). Elle renvoie aux possibilités, ouvertes ou non, et aux impossibilités (à relier avec le temps 3) d'un passé dont l'issue n'était pas alors l'unique voie ayant débouché sur notre présent.

61 Des recherches en ergonomie (Pueyo, 2014) soulignent l'intérêt d'un plan d'analyse abordant avec les travailleurs les voies de bifurcations du passé. Cette dimension est l'une de celles qui permettent de «nouer les fils du passé » (pp. 27-36) pour comprendre l'activité 
actuelle dans la complexité des dynamiques du travail et des mutations des systèmes. Pour les travailleurs, ces voies du passé peuvent se rapporter à une appréciation, un évènement ayant eu lieu ou pas, à une décision prise ou non. Elles réfèrent aux bifurcations et aux actions possibles et impossibles du passé, qui ont du sens au moment présent car ils représentent le non-réalisé, le non-choisi ou ce qui n'a pu être choisi, et les "voies abandonnées» (idem). Ces voies de bifurcations concernent aussi «ce que l'on n'avait pas à l'esprit », à ce moment du passé. En ouvrant des réflexions « sur ce que ça aurait changé ", elles amènent aussi les travailleurs à exprimer de "nouveaux projets » (ibidem).

\subsubsection{Le temps des alternatives passées en horticulture}

En horticulture et en pépinières, les travailleurs ont recours à ce temps uchronique lorsqu'ils évoquent certains choix libres ou contraints (les leurs ou ceux des autres) dans un passé plus ou moins lointain, les oublis, ou encore les attentes ne débouchant pas sur l'évènement attendu. C'est par cette conception temporelle qu'ils sont amenés à reconsidérer le passé, à la lumière des voies finalement empruntées et des évènements du présent, comme le montrent les extraits d'entretiens présentés dans l'encadré 4 .

Encadré 4 : Conception d'un temps uchronique « des alternatives passées » chez les chefs de culture (Temps 4).

Box 4: Horticulture managers' conception of an uchronic time of "past alternatives" (Time 4)

Le diagnostic porté sur une situation par les chefs de culture peut les amener à relier le présent et des évolutions en cours avec des états passés, non diagnostiqués ou auxquels il n'a pas été possible de répondre. Ainsi, au sujet de l'évolution des plantes : «Des fois on peut se faire déborder. Les plantes poussent très, très vite. Si le tuteurage n'est pas bien fait, n'a pas été fait, des fois après, on se retrouve avec tout un lot de plantes qui a mal poussé, on va dire, qui n'a pas été taillé. Et à ce moment-là, si elle n'a pas été taillée, elle n'est pas fournie » (BE). Ce chef de culture se réfère à des moments bousculés du passé et à des actions non réalisées, qu'il relie à des impossibles survenus depuis : "Donc après, on ne peut plus rattraper, on ne peut plus revenir. On a perdu du temps »

Les bifurcations manquées sont parfois précisément situées dans le passé : «Quand un lot monte trop haut, il faut tailler parce qu'autrement il se dégarnit par la base. Et des fois il faut le faire au bon moment. Des fois le bon moment, au printemps, on a autre chose à faire qui est aussi urgent. Et alors à ce moment-là, c'est un peu trop tard ». Le chef de culture situe l'alternative manquée dans le passé par rapport à un "moment» dans l'évolution des plantes qui aurait exigé (estimation ex-post) des actions.

Ce retour sur les alternatives du passé peut aussi amener à confirmer les choix réalisés : "Donc le rempotage, on aurait pu en faire plus, le désherbage aussi et le tuteurage aussi. (...), mais on a préféré éparpiller un peu. Il faut bien faire un peu tout ».

Ces exemples montrent que ce temps uchronique est parfois à repérer en creux, dans l'expression de ce qui n'a pas été fait (cf. dans l'encadré 4, les plantes non taillées), sans qu'un développement sur ce qui aurait pu être ne soit toujours explicitement exprimé (les plantes taillées auraient bien poussé et auraient été prêtes à temps). C'est le «temps perdu ", celui du «trop tard» ou encore de ce qui a été "évité». C'est aussi le temps des évènements «manqués », de ce qui « aurait dû » arriver, et celui du «si on avait vu... ou fait 
». Nous verrons dans l'extrait d'activité que c'est aussi le temps des « oublis » et de ce qui " aurait dû » être fait (cf. 5.). Ainsi, les horticulteurs peuvent identifier des bifurcations possibles ou impossibles d'un passé qui aurait pu être autre, et qui prend du sens dans la situation présente, du fait des suites et des conséquences maintenant connues, ainsi que de leurs réflexions actuelles sur l'action qu'ils envisagent.

Cette analyse met aussi en évidence l'association de différentes conceptions temporelles. Ce temps uchronique (temps 4) est ici articulé avec l'appréciation de la croissance des plantes par un temps tiré par le futur (temps 2), en référence à la période de printemps repérée dans le calendrier (temps 1 ).

Il s'agit maintenant de montrer comment ces conceptions du temps permettent de caractériser les liens entre cadres temporels considérés par les chefs de culture, ainsi que la forme de cohérence entre ces cadres qu'ils constituent, dans la complexité de leur milieu temporel.

\section{Des configurations redoutées pour leurs dynamiques tourbillonnaires}

Dans la diversité des situations qu'ils gèrent, les chefs de culture ont identifié des configurations d'organisation particulières, qu'ils caractérisent en mobilisant des combinaisons variées de conceptions temporelles. Nous présentons en particulier deux de ces configurations, qu'ils redoutent pour leurs dynamiques tourbillonnaires d'exigences menant au débordement.

\subsection{Après un hiver doux, lorsque les herbes envahissent les plantes}

67 Précisons les principaux traits d'une configuration redoutée décrite dans la pépinière $\mathrm{BE}$. "Les hivers cléments ", explique le chef de culture en entretien, «c'est aussi pour les herbes... ». Il associe ainsi le temps du calendrier saisonnier (temps 1 poussé par le passé) avec l'ordre inéluctable du développement des herbes dans les pots (temps 2 d'un ordre temporel). De plus, selon lui, les conditions climatiques ne sont pas seules en cause dans cette évolution, car cette croissance des herbes (temps 2) est à comprendre en considérant des soins aux plantes non réalisés (temps 4 des alternatives du passé). Ces retards accumulés ont conduit à une bifurcation pour des lots "n'ont pas bien poussé », et qui ont laissé la place aux herbes dans les pots.

Par suite, lorsque les ventes redémarrent au printemps, certaines plantes sont envahies par les herbes, et il devient impossible (temps 3 construit, ouvrant ou fermant des possibles) de les vendre en l'état. Au moment où il faut assurer la sortie d'hivernage de nombreux lots et intercaler les mises en culture suivantes avec les ventes, des travaux de soins supplémentaires s'imposent, ainsi que le rattrapage du désherbage (temps 2 d'un ordre temporel).

Cette configuration est redoutée par le chef de culture car elle se solde par un travail de désherbage accru, devenu plus long, plus difficile et plus pénible, en présentant des risques pour la santé. De plus, l'écart entre ce qui est à faire et ce qu'il parvient à réaliser se creuse, d'autant que les saisonniers affectés au désherbage ne peuvent plus aider aux mises en culture ni aux expéditions. Une dégradation de la qualité de la production et des 
expéditions peut en résulter, avec des retours clients qui peuvent en retour aggraver le débordement.

\subsection{Lorsqu'un vent d'automne fait chuter les plantes hautes}

70 L'une des observations réalisées auprès de ce chef de culture a permis d'aborder dans l'activité une autre configuration redoutée identifiée en entretien: un épisode de vent fort faisant chuter les plantes déjà hautes en pleine période de vente, avec des risques d'atteintes pour leur qualité. Le chef de culture avait expliqué : «Après on peut avoir des dégâts d'un coup, parce que ça a séché les pots... » (précisons qu'une plante couchée ne reçoit plus l'arrosage par aspersion et peut donc très vite se dégrader). Il reliait cette situation à des opérations de relevage urgent qui viennent s'ajouter aux travaux saisonniers de mise en culture et de vente, à une période où les lots à suivre sont nombreux. Ces configurations sont épuisantes pour tous, d'autant que des rafales peuvent à nouveau coucher les plantes avant qu'il ait eu le temps de déclencher l'arrosage qui leste le terreau et limite les rechutes.

71 Examinons la situation observée ce mardi d'octobre, alors que le vent persiste. Entre 7h50 et $8 \mathrm{~h}$, le chef de culture fait le point sur la situation et affecte les trois ouvriers au relevage des lauriers à terre :

«Cette nuit, du [vent] marin, oui... Nous on va relever. Hier on n'a pas fini de tout relever. Pour la commande [en attente depuis la veille], ce n'est pas sûr... On ne va pas pouvoir la préparer de suite... ».

Un peu plus tard, sur la parcelle, il explique : «Le vent là, n'a pas tout fait tomber, c'est celui de samedi, et on n'a pas ramassé hier... ». Dès cet état de la situation, on repère dans ses propos la mobilisation de différentes conceptions temporelles : il associe le vent de «cette nuit » et de « samedi » (temps 1 poussé par le passé), au relevage non réalisé la veille (temps 4 des alternatives du passé) ; tenant compte d'une commande qui pourrait être à préparer dès confirmation (temps 3 ouvrant ou fermant des possibles). Les préoccupations concernant l'évolution des plantes en souffrance (temps 2 d'un ordre temporel) ne sont pas directement explicitées dans cet extrait, mais elles sont cependant très présentes et transparaissent durant la journée à travers des actions (examiner le feuillage d'un lot en passant, soupeser un pot, toucher le terreau...), ce qui est confirmé par ses verbalisations du type "là ils ont soif... ».

Comme décrit dans la configuration redoutée, cette situation est d'autant plus délicate à gérer que les lauriers invendus sont clairsemés sur les parcelles, mais encore nombreux, et étant hauts et feuillus, ils offrent prise au vent. Toutefois, le chef de culture ajoute à cet assemblage une composante biosphérique qui semble plutôt favorable : «Comme il pleut, ça va tout remouiller donc c'est bien " (temps 2). Ainsi, il mobilise cette dynamique en tant qu'appui, car la pluie devrait lester les pots au fur et à mesure du relevage. Soulignons que cette pluie compliquera par ailleurs le déroulement des travaux, nous y revenons cidessous.

Dans la suite de la matinée, le chef de culture articule tout à la fois : une poursuite de la planification de la journée et des ajustements des consignes aux ouvriers tout en guettant la confirmation de la commande en attente (il se rend pour cela plusieurs fois au service commercial), une surveillance des différents lots et de l'évolution de la météo, avec des tournées sur les parcelles et des ajustements des automates d'arrosage, et un suivi des travaux en cours, avec en particulier le relevage qui s'impose. À 8h32, la pluie augmente, 
et il réaffecte les ouvriers dans les serres à la taille et la pose de tuteurs, lui-même assurant ensuite seule la poursuite du relevage au fil de ses déplacements dans la pépinière.

On relève de nombreuses traces d'une gestion active de son milieu temporel, en particulier avec une recherche permanente d'ouvertures de possibles (temps 3), par exemple au cours du relevage avec: "En relevant, on peut faire de la place». Le regroupement des lauriers lui permet tout à la fois de limiter leurs rechutes, de faciliter les soins, et de libérer de l'espace sur la parcelle pour les prochaines mises en culture.

En association avec cette recherche de possibles, le temps uchronique (temps 4) est aussi largement mobilisé au fil de la journée, comme à 10h26, lorsqu'il regarde sa montre et s'exclame: "Comme il ne pleut plus, j'aurais dû les envoyer au Ferrichel ${ }^{12}$, c'est ce que j'ai oublié ». Dans la complexité de la matinée, il réalise soudain (temps 1 de l'horloge) qu'il aurait dû mettre à profit plus tôt (temps 4) une fenêtre d'accalmie des intempéries qu'il juge éphémère (temps 2) pour faire réaliser un traitement sur des Grevillea. Quelques minutes après, il réaffecte les ouvriers (dont l'un était sur une parcelle et les deux autres dans des serres) à ce travail : "Alors opération commando. Le temps qu'il ne pleut pas, on va vite (...)». Avec cette formule qui traduit une attente de réactivité, il incite les ouvriers à basculer sur un mode d'urgence.

Les Grevillea ont effectivement pu être traités ce matin-là, mais cet épisode n'est pas sans conséquence. Il craint pour la qualité des lierres dont le tuteurage est interrompu, celle des nombreux lauriers encore à terre en fin de journée, et celle d'un lot d'Eleagnus en souffrance qui a échappé à sa surveillance. De plus, du retard a été accumulé dans différents travaux. Des conséquences pour la santé et la sécurité de chacun sont aussi mises en évidence. Les ouvriers expriment fatigue et lassitude suite aux réaffectations " urgentes ", d'autant qu'une ouvrière interrompue dans le tuteurage sous abri a dû travailler sans gants ni blouson au traitement des Grevillea. Le chef de culture ayant pris en charge la suite du relevage, avec d'autres travaux sous la pluie, a lui-même déployé un fort engagement physique durant plusieurs heures.

77 Ainsi, pour gérer les situations, les chefs de culture mobilisent différentes conceptions temporelles pertinentes pour eux. Cependant ils redoutent ces dynamiques tourbillonnaires dont ils ne peuvent s'extraire lorsqu'elles sont engagées, faute de prises pour influer sur les contraintes concernées. Elles les emmènent vers un milieu temporel qu'ils ne peuvent plus gérer en aménageant des issues cohérentes selon eux. Leur expérience ne semble alors plus une ressource, avec pour conséquences des risques qui se profilent pour la production et pour leur santé et celle des ouvriers.

\section{Discussion. Tenir les cadres par des conceptions temporelles combinées : quels apports et quelles prises pour la recherche et l'action?}

Cette recherche s'inscrit dans une forme d'analyse ergonomique de l'activité qui considère les situations comme des fenêtres où s'entrecroisent des dynamiques aux échelles de temps beaucoup plus vastes et complexes. Pour les élucider il faut se doter d'outils spécifiques et pluridisciplinaires qui permettent d'aborder leurs multiples dimensions entremêlées relatives aux individus, aux collectifs, et aux systèmes de travail, ainsi que leurs évolutions et leurs effets (Pueyo, 2012, 2014). La situation est aussi une 
occasion de saisir des contradictions entre des dynamiques portées par des logiques diverses, issues de différents niveaux décisionnels. Dans les périodes de changement, certaines logiques gestionnaires très orientées vers le présent et le court terme peuvent en particulier envahir l'activité, en générant des dyschronies dans les associations temporelles que chacun cherche à produire au fil de sa vie professionnelle (Gaudart, 2014).

79 L'analyse des cadres temporels que nous proposons cherche aussi à déplier les différentes dynamiques des situations, et à prendre en compte des échelles qui dépassent la focale des observations. Son objectif a été d'appréhender les dynamiques de court et long termes, mais aussi d'explorer une autre dimension qualitative de ces dynamiques. Avec l'approche multimodale du milieu temporel constitué et géré par les travailleurs, nous examinons plus particulièrement une forme d'épaisseur temporelle des situations, du point de vue de l'activité.

Les quatre conceptions temporelles que nous avons distinguées sont fondées sur les formes d'expression temporelle dégagées des situations, à partir d'entretiens et de suivis de l'activité. Elles permettent d'éclairer les modalités variées et combinées par lesquelles les chefs de culture appréhendent les cadres temporels et leurs dynamiques. Ainsi, nous mettons en évidence la conception d'un temps poussé par le passé, fixé d'avance par l'horloge et dans le calendrier (temps 1), souvent combiné par les chefs de culture à un temps tiré par le futur, c'est-à-dire une projection de ce qui arrivera et doit arriver (temps 2). De plus, dans la complexité et l'incertitude, ils mobilisent d'autres formes de prise en compte des dynamiques de l'activité, avec la conception d'un temps d'ouverture de possibles (temps 3), et d'un temps uchronique de ce qui aurait pu ou aurait dû être fait ( temps 4).

81 Leur mobilisation combinée ne relève pas seulement de diagnostics successifs au fil de l'activité, mais elle traduit une démarche active de mise en lien de cadres temporels aux qualités variées et non homogènes, pour produire d'autres significations et d'autres intentionnalités. Ces différentes conceptions temporelles éclairent «ce que l'opérateur fait, aussi ce qu'il ne peut pas faire, ce qu'il ne fait pas, ce qu'il empêche, ce qui l'empêche, ce qu'il fait advenir, ce qu'il cherche, ce qu'il pourrait faire, ce qu'il faudrait qu'il fasse..., et dans la situation, toutes les formes du réel qui le font agir... » (Hubault, 2003, p. 214). Ainsi, nous dégageons une visée d'ensemble de leurs actions dans la complexité du milieu temporel, qui est de toujours chercher des ouvertures cohérentes pour poursuivre et agir.

Dans leurs situations mouvantes et évolutives, l'action ne peut se référer uniquement à des composantes situationnelles déjà déterminées qui permettraient de poursuivre des fins clairement et définitivement identifiées. Elle nécessite toujours invention et création dans des situations toujours changeantes. Cependant, il ne s'agit pas d'actions opportunistes, et encore moins de libre improvisation. Les analyses montrent au contraire une gestion dynamique suivie, au cours de laquelle ils cherchent en permanence à tisser des liens sous plusieurs modalités temporelles.

En témoignent par exemple les réflexions de plusieurs chefs de culture concernant le recours aux agendas devenu inopérant et leur renoncement à la rédaction d'un planning formel, et qui expliquent au fil de l'entretien se fonder sur des repères qu'ils ont «en tête » du fait de leur expérience. D'autres font tout de même état de plans, établis pour certaines grandes lignes du travail (par exemple des repères sur un calendrier mural), quitte à devoir les ajuster régulièrement (gomme, ratures, post-it...). C'est ce que montre 
aussi une autre recherche dans ce même secteur horticole, où le planning des affectations qu'une encadrante établit est précieux pour la prescription qu'elle conçoit à destination des ouvriers, et cela même s'il est toujours à reprendre au fil d'une journée (Gotteland, Pueyo, \& Béguin, 2015). En effet ce planning, qu'elle sait être "périmé » dès sa formalisation, fait l'objet de multiples réajustements plus ou moins formalisés sur le papier. Il apparait moins établi pour être suivi que pour orienter son action (Suchman, 1987). Il permet aussi de cristalliser ponctuellement certaines options d'organisation dans la dynamique des situations, et de garder ainsi une trace des options du moment pour pouvoir y revenir. Ainsi, dans certaines circonstances, les chefs de culture ont besoin de mobiliser des cadres temporels en tant que repères (provisoirement) tangibles.

Une interrogation porte sur le rôle que les configurations d'organisation que nos analyses ont dégagées pourraient avoir, en tant que repères supports à la gestion du milieu temporel. Elles ont été identifiées par les chefs de culture, en réfléchissant sur leur activité sur un plan général. Elles sont le fruit de l'expérience qu'ils ont pu constituer en revenant sur des situations vécues pour en tirer des enseignements (Pueyo, 2012). Une hypothèse est que ces configurations temporelles structurent leur pensée et leurs décisions dans l'activité. Nous le montrons en particulier pour certaines, redoutées pour les difficultés qu'elles leur permettent de prédire. Les chefs de culture identifient les conditions de survenue de ces configurations redoutées à partir de leur expérience, et ils savent par cette expérience qu'ils n'ont pas de possibilité pour les éviter et enrayer leurs dynamiques tourbillonnaires. Ils s'attendent alors à l'impossibilité de trouver une issue acceptable dans leur activité. Et cela d'autant plus que, trop souvent, ils n'ont qu'un accès restreint aux informations concernant les cadres temporels qu'ils doivent gérer, et ils doivent « faire avec » une imprécision récurrente dans les informations ou le niveau de certitude qu'ils parviennent à obtenir. Soulignons que nous n'avons pas pour autant constaté de fatalisme de leur part en matière de gestion temporelle, mais tout au contraire une recherche de création de formes d'influence technique et sociale toujours renouvelées pour chercher des issues favorables pour la production et pour les équipes.

Dans une perspective ergonomique de transformation du travail, la réflexion doit porter sur les exigences du travail plus ou moins malléables qui permettent ou au contraire entravent cette gestion temporelle recherchant des ouvertures et des issues favorables dans le milieu temporel. Les pistes travaillées avec les partenaires projets et auprès des entreprises dans lesquelles nous sommes intervenus ont concerné certains outils et indicateurs de gestion qui, en constituant des critères non homogènes d'évaluation de l'action, entravent la gestion temporelle ; nous avons aussi plus largement questionné les choix de positionnement commercial, technique et de niveau qualité qui influent sur la survenue des configurations redoutées (Pueyo, \& Zara-Meylan, 2012; Zara-Meylan, 2013a). Cependant, et c'est sur quoi nous insistons dans le cadre de cet article, ces transformations passent par un éclairage du rôle clé des chefs de culture, et par la mise en évidence de cette gestion multimodale de leur milieu temporel. Ainsi, et pour ne citer qu'un exemple, ils sont souvent tenus à distance de l'élaboration et des ajustements du planning de culture, alors qu'ils devraient pouvoir y contribuer, et même influer sur ses inflexions d'année en année, en tant qu'interlocuteurs pertinents. La gestion du milieu temporel relève d'un véritable savoir-faire, central dans le travail d'organisation qui est au cœur de leur métier (Gotteland, Zara-Meylan, \& Pueyo, à paraitre), et qu'il faut faire reconnaitre pour en montrer les apports et aussi les besoins. 
De nombreuses questions sur l'agir temporel sont encore à explorer, en particulier dans des situations dynamiques où les travailleurs ont à gérer des imbrications complexes de cadres temporels dont ils ne peuvent que trop rarement espérer l'harmonisation, et où l'expérience est aussi celle de configurations redoutées qui sont tout de même à gérer malgré leurs tentatives pour en éviter la survenance. Les recherches visant à élucider les conditions qui favorisent ou pas l'agir temporel doivent être poursuivies. Elles cherchent en particulier à répondre aux questions suivantes : dans la diversité des situations vécues, comment et à quelles conditions l'expérience de la gestion multimodale du milieu temporel se constitue-t-elle ? Et comment ce champ d'expérience (Chesneaux, 2004) est-il mobilisé pour trouver des issues acceptables dans l'actualité de l'activité et avec quels horizons temporels?

\section{BIBLIOGRAPHIE}

Amossé, T., Cartron, D., Castell, L., Célérier, S., Pueyo, V., Wolff, L., \& Zara-Meylan, V., (2014). Formes d'organisation et santé au travail en entreprise. Unpublished Rapport d'une recherche financé par le CEE et la Dares, suite aux enquêtes Reponse. CEE.

ANEFA. (2006a). Fiche métier : Chef de culture en pépinière. Autre dénomination : Responsable pépinière. Retrieved from http://anefa.org.

ANEFA. (2006b). Fiche métier : Chef de culture horticole. Autre dénomination : Responsable de culture horticole. Retrieved from http://anefa.org.

Aranda, D. (2010). Le Jeu des temporalités dans les utopies et uchronies de Rétif de la Bretonne. Temporalités, 12, http://temporalites.revues.org/

Askenazy, P., Cartron, D., de Coninck, F., \& Gollac, M. (Eds.). (2006). Organisation et intensité du travail. Toulouse : Octarès.

Beck, U. (2001). La société du risque. Sur la voie d'une autre modernité (Traduit par L. Bernardini). Paris : Alto Aubier.

Béguin, P. \& Clot, Y. (2004). L'action située dans le développement de l'activité. @ctivités, 1(2), 27-49, http://activites.revues.org/1237

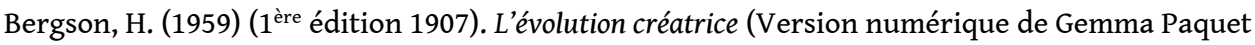
d'après une édition PUF, 1959). Chicoutimi : Cégep.

Bron, G., Duclaud, E., \& Toussaint, J.-P. (2004). L'entreprise horticole - Approche globale et environnementale. Dijon : Educagri.

Cau-Bareille, D. (2012). Travail collectif et collectif de travail au fil de l'âge : des ressources et des contraintes. In A.-F. Molinié, C. Gaudart, \& V. Pueyo (Eds.), La vie professionnelle : âge, expérience et santé à l'épreuve des conditions de travail (pp. 181-204). Toulouse : Octarès.

Cellier, J.-M., De Keyser, V., \& Valot, C. (1996). La gestion du temps dans les environnements dynamiques. Paris : PUF. 
Chesneaux, J. (1983). Despotisme du temps, écrasement du temps, résistance du temps. In J. Chesneaux (Ed.), De la modernité (pp. 33-54). Paris : La Découverte- Maspéro.

Chesneaux, J. (1996). Habiter le temps - Passé, présent, futur, esquisse d'un dialogue politique. Paris : Bayard.

Chesneaux, J. (2004). Cinq propositions pour appréhender le temps. Temporalités 0, 107-118, http://temporalites.revues.org/.

Delgoulet, C., Kerguelen, A., \& Barthe, B. (2000). Vers une analyse intégrée des communications et des actions au travail : quelles modalités de leur mise en relation? Communications et travail. Actes du 35 e congrès de la Self (pp. 363-375). Toulouse : SELF.

Demazière, D. \& Dubar, C. (2004). Analyser les entretiens biographiques. Québec : Les Presses de l'Université de Laval.

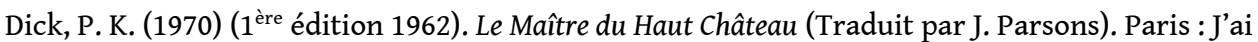
lu.

Dubar, C. (2008). Temporalité, temporalités : philosophie et sciences sociales. Temporalités, 8 , http://temporalites.revues.org/.

Dubar, C. (2014). Du temps aux temporalités : pour une conceptualisation multidisciplinaire, Temporalités, 20, http://temporalites.revues.org/2942

Duval, R. (1990). Temps et vigilance. Paris : Librairie Philosophique J. Vrin.

Gaudart, C. (2014). Les relations entre l'âge et le travail comme problème temporel. Pistes, 16(1), https://pistes.revues.org/

Gotteland, C., Pueyo, V., \& Béguin, P. (2015). Concevoir des cadres pour faire et faire faire : l'activité d'encadrement dans une entreprise horticole, @ctivités, 12(1), 24-45, http:// activites.revues.org/983

Gotteland, C., Zara-Meylan, V., \& Pueyo, V. (à paraître). Le travail d'articulation des encadrants de proximité : Quels enjeux de production et de santé en horticulture ? Pistes.

Grossin, W. (1996). Pour une science des temps. Introduction à l'écologie temporelle. Toulouse : Octarès.

Grossin, W. (1998). Temps, vitesses, accélérations, urgences et recherches. Temporalistes, 38, 3-4, http://temporalistes.socioroom.org/

Hatzfeld, N. (2008). Au-delà de la perspective, cartographier le passé. Temporalités, 8, http:// temporalites.revues.org/ .

Hénaff, M. (2003). Le don, la dette et le temps. In F. Ost, S. Agacinski, E. Klein, \& Y. Schwartz (Eds.), Figures du temps (pp. 35-57). Paris : Parenthèses.

Hubault, F. (2003). La ressource du risque. In F. Hubault (Ed.), Travailler, une expérience quotidienne du risque? (pp. 207-220). Toulouse : Octarès.

Joas, H. (2004) (1 ère édition 1999). La créativité de l’agir (Traduit par P. Rusch). Paris : Édition du Cerf.

Klein, E. (2003). Le temps et les choses. In F. Ost, S. Agacinski, E. Klein, \& Y. Schwartz (Eds.), Figures du temps (pp. 13-34). Paris : Parenthèses.

Klein, E. (Ed.). (2009) (1 1 ère édition 2004). Les tactiques de Chronos. Paris : Flamarion. 
Lallement, M. \& Ramos, J.-M. (2010). Réinventer le temps. Temporalités(12), http:// temporalites.revues.org/

Le Moigne, J.-L. (1997). Les trois temps de la modélisation des éco-systèmes : l'entropique, anthropique et le téléologique, Les temps de l'environnement (Vol. Session 3, 4 \& 5, Conférences plénières, pp. 615-618). Toulouse.

Le Moigne, J.-L. (1998). Temps de travail et travail du temps : « on ne peut pas ne pas changer », Temps et travail. Actes du XXXIIIe Congrès de la SELF (pp. 1-10). Paris.

Leroi-Gourhan, A. (1973) (1 ${ }^{\text {ère } e ́ d i t o n ~ 1945) . ~ E v o l u t i o n s ~ e t ~ t e c h n i q u e s . ~ T o m e ~} 2$ : Milieu technique (Vol. 2). Paris : Albin Michel.

Mendez, A., Bidart, C., Brochier, D., Correia, M., Garnier, J., Gilson, A. et al. (2010). Chapitre introductif. Vers un système d'analyse des processus. In A. Mendez (Ed.), Processus. Concepts et méthode pour l'analyse temporelle en sciences sociales (pp. 11-26). Louvain-la-Neuve, Belgique : Bruyant-Academia.

Michon, P. (2014). Rythme et sociologie : une introduction. In S. Monchatre \& B. Woehl (Eds.), Temps de travail et travail du temps (pp. 41-60). Paris : Publications de la Sorbonne.

Molinié, A.-F., Gaudart, C., \& Pueyo, V. (Eds.). (2012). La vie professionnelle : âge, expérience et santé à l'épreuve des conditions de travail. Toulouse : Octarès.

Molinié, A.-F. \& Pueyo, V. (2012). Les dynamiques temporelles des relations santé travail, et le fil de l'âge. In A.-F. Molinié, C. Gaudart, \& V. Pueyo (Eds.), La vie professionnelle : âge, expérience et santé à l'épreuve des conditions de travail (pp. 237-255). Toulouse : Octarès.

Montmollin, de M. (1997). Vocabulaire de l'ergonomie. Toulouse : Octarès.

Morin, E. (2005). Introduction à la pensée complexe. Paris : Seuil.

Owen, C. (2007). Analyser le travail conjoint entre différents systèmes d'activité. @ctivités, 5(2), 70-89, http://activites.revues.org/2053

Pueyo, V. (1999). Régulations de l'efficience en fonction de l'âge et de l'expérience professionnelle dans la gestion du contrôle qualité dans la sidérurgie. Unpublished Thèse de doctorat d'ergonomie, EPHE, Paris.

Pueyo, V. (2012). Quand la gestion des risques est en péril chez les fondeurs. In A.-F. Molinié, C. Gaudart, \& V. Pueyo (Eds.), La vie professionnelle : âge, expérience et santé à l'épreuve des conditions de travail (pp. 257-284). Toulouse : Octarès.

Pueyo, V. (2014). Le contrat de base : une proposition pour nouer les fils du passé et penser le futur du travail. Actes du séminaire Creapt 2012. Travail passé, activité et santé d'aujourd'hui : quels impacts des situations de travail ? Rapport de recherche ${ }^{\circ} 88$ (pp. 27-43). Paris : Centre d'Etudes de l'Emploi. http://www.cee-recherche.fr/publications/rapport-de-recherche/travailpasse-activite-et-sante-daujourdhui-quels-impacts-des-situations-de-travail

Pueyo, V. \& Zara-Meylan, V. (2012). Impacts d'outils de gestion sur la conduite de cultures en pépinière. Activités, 9(1), 1-20, http://www.activites.org

Renouvier, C. (1879, 2e édition revue et augmentée) (1 ère édition 1857). Uchronie. Utopie dans l'Histoire.

Rolle, P. (2014). Les temps du travail et le travail du temps. Réflexions sur l'objet de la sociologie du travail. In S. Monchatre \& B. Woehl (Eds.), Temps de travail et travail du temps (pp. 25-40). Paris : Publications de la Sorbonne. 
Shippers, T. K. (1995). Le facteur anthropique, concept carrefour entre déterminisme naturaliste et possibilisme social. Acta Ethnographica Hungarica, 40(1-2), 245-252.

Suchman, L. (1987). Plans and situated actions: the problem of human machine interaction. Cambridge : Cambridge University Press.

Teiger, C. (1993). L'approche ergonomique : du travail humain à l'activité des hommes et des femmes au travail. Education Permanente, 116, 71-96.

Valot, C. (1998). Métacognition et connaissances métacognitives. Intérêt pour l'ergonomie. Unpublished Thèse de doctorat de nouveau régime, spécialité Ergonomie, Toulouse.

Vatin, F. (2014). Le temps mesure-t-il le travail ? Propos épistémologiques. In S. Monchatre \& B. Woehl (Eds.), Temps de travail et travail du temps (pp. 61-69). Paris : Publications de la Sorbonne.

Volkoff, S. (2005). Des comptes à rendre : usages des analyses quantitatives en santé au travail pour l'ergonomie. In S. Volkoff (Ed.), L'ergonomie et les chiffres de la santé au travail : ressources, tensions et pièges (pp. 3-74). Toulouse : Octarès.

Volkoff, S. (2008). L'intensification disperse les problèmes de santé. In G. De Terssac, C. SaintMartin, \& C. Thébaud (Eds.), Travail, organisation, santé : une question de précarité (pp. 29-40). Toulouse : Octarès.

Volkoff, S. (2012). Le travail, en évolutions. In A.-F. Molinié, C. Gaudart, \& V. Pueyo (Eds.), La vie professionnelle : âge, expérience et santé à l'épreuve des conditions de travail (pp. 31-42). Toulouse : Octarès.

Weill-Fassina, A. (1990). Activités et compétences professionnelles. In M. Dadoy, C. Henri, B. Hillau, G. de Terssac, J.-F. Troussier, \& A. Weill-Fassina (Eds.), Les analyses du travail ; enjeux et formes (Vol. 54, pp. 145-148). Paris : Cahiers du Cereq.

Weill-Fassina, A. \& Valot, C. (1998). Le métier, ça va, mais le problème c'est c' qu'y a autour. In M.F. Dessaigne \& I. Gaillard (Eds.), Des évolutions en ergonomie (pp. 75-87). Toulouse : Octarès (1è parution Gerra, 1997, Actes du XXXIIe Congrès de la SELF).

Zara-Meylan, V. (2012a). Modalités de gestion du milieu temporel dans une conduite de processus multiples en situation dynamique : une recherche dans des entreprises horticoles. Thèse de doctorat en Ergonomie, Cnam, CEE, Noisy-le-Grand. https://tel.archives-ouvertes.fr/tel-00795233

Zara-Meylan, V. (2012b). Organisation et mobilisation des collectifs pour la gestion des risques : des modalités contrastées chez des monteurs installateurs et des horticulteurs. In A.-F. Molinié, C. Gaudart \& V. Pueyo (Ed.), La vie professionnelle : âge, expérience et santé à l'épreuve des conditions de travail (pp. 205-222). Toulouse : Octarès. http://www.cee-recherche.fr/publications/ouvrages/lavie-professionnelle

Zara-Meylan, V. (2013a). Faire face aux imprévus sans être pris au dépourvu : le cas des chefs de culture dans de petites entreprises horticoles. Sociologies Pratiques, 26, http://www.cairn.info/ revue-sociologies-pratiques.htm

Zara-Meylan, V. (2013b). Modalidades de gestão do meio temporal em uma condução de processos múltiplos em situação dinâmica ; uma pesquisa em empresas de horticultura, Resumos de teses. Laboreal, IX(1), 60-65, http://laboreal.up.pt

Zarifian, P. (2001). Temps et Modernité. Le temps comme enjeu du monde moderne. Paris : L'Harmattan. 


\section{NOTES}

1. Société d'Ergonomie de Langue Française.

2. Des représentations chronologiques familières aux ergonomes, réalisées à partir de relevés d'actions et d'interactions fondés sur des observations de l'activité de travailleurs (Delgoulet, Kerguelen, \& Barthe, 2000).

3. Entrée intitulée «Temps (dimension temporelle du travail)», dans le «Vocabulaire de l'ergonomie ", par cet auteur.

4. Cf. Méthodologie.

5. Centre de recherche sur l'expérience, l'âge et les populations au travail.

6. Nous nous appuyons sur trois projets auxquels nous avons participé dans le cadre du Gis Creapt, sous la direction scientifique de V. Pueyo, en partenariat avec des intervenants en prévention des risques professionnels et en formation, la fédération professionnelles, et avec des dirigeants d'entreprises de ce secteur, de 2006 à 2011 : «Agriquadra », un projet Equal sur les liens vieillissement et travail dans des secteurs agricoles; "L'évaluation des risques professionnels dans les pépinières ", sur une demande du Bureau Réglementation et Travail du Ministère de l'Agriculture et de la Pêche; "Comment relier prévention des risques et préoccupations productives de petites entreprises », avec la MSA du Languedoc.

7. Cette expression est inspirée du «vol redouté », un concept de Claude Valot (1998), introduit pour analyser l'activité métacognitive des pilotes en aéronautique: «Ce qui est redouté par l'opérateur, et source de complexité subjective, est de se voir entraîné dans un domaine de moindre compétence où il serait confronté à des aspects du contrôle de ce processus qu'il ne serait pas en mesure de maîtriser » (p. 44). Soulignons déjà que, contrairement aux pilotes qui parviennent le plus souvent à éviter le vol redouté, les chefs de culture sont souvent tenus de gérer des configurations redoutées (cf. 5-).

8. «Le disponible» adressé aux clients est la liste des plantes dont on souhaite favoriser la commercialisation à un moment donné, en mettant en avant certaines conditions saisonnières (arbres en racines nues pendant le repos végétatif d'hiver...) ou leurs caractéristiques de développement ou de floraison (lauriers roses en boutons, rosiers en boutons fleurs...).

9. Des précisions sur ces différentes acceptions et sur les liens entre utopie et uchronie figurent dans le numéro spécial de la revue Temporalités, 2010, Utopies/Uchronies, vol 12.

10. Ajoutons que cet ouvrage comporte une uchronie dans l'uchronie, car l'auteur imagine que les forces de l'Axe ont gagné la guerre en 1944 (uchronie principale), et l'un de ses personnages, un écrivain de cette époque alternative, écrit une uchronie selon laquelle les alliés auraient gagné le conflit.

11. Certains auteurs ont opté pour d'autres acceptions du terme uchronie, l'élargissant à des réflexions concernant les "voyages" dans le temps (Klein, 2009, pp. 163-172), dans des mondes parallèles ainsi qu'à des projections de la littérature d'anticipation imaginant la société dans l'avenir (Aranda, 2010). Nous excluons dans cette recherche ces acceptions. Nous restons ancrés sur la définition initiale de C. Renouvier qui fait référence (Lallement \& Ramos, 2010).

12. Intrant utilisé pour répondre à un diagnostic de chlorose ferrique. 


\section{RÉSUMÉS}

Cette contribution a été réalisée à partir de recherches en ergonomie ayant fait l'objet d'une thèse sur les modalités de gestion temporelle en situation dynamique. Nous y présentons une catégorisation temporelle issue de plusieurs disciplines en sciences sociales, qui est opérationnalisée pour analyser l'activité de chefs de culture en horticulture. Nous précisons tout d'abord les exigences temporelles du travail des chefs de culture en termes de cadres temporels entremêlés qu'ils gèrent dans un «milieu temporel » complexe. À partir d'entretiens réalisés sur neuf sites puis d'observations systématiques de l'activité de cinq d'entre eux, nous analysons ensuite les différentes modalités par lesquelles ils appréhendent ces cadres temporels et font évoluer leur milieu temporel. Les résultats nous amènent à proposer quatre conceptions temporelles complémentaires pour comprendre l'agir temporel multimodal en situation dynamique. Notre modèle distingue ainsi : un temps "poussé par le passé » de l'horloge et du calendrier (temps 1), un temps » tiré par le futur» d'un ordre temporel (temps 2), un temps «construit par le présent» et ouvrant l'avenir (temps 3) et enfin un temps uchronique «des alternatives passées » (temps 4). Ces conceptions temporelles sont mobilisées pour analyser des configurations de conditions temporelles identifiées et gérées par ces encadrants de proximité dans leur activité et celle de l'équipe. Certaines de ces configurations mènent à des difficultés et des risques pour la production ou pour leur santé.

This contribution leans on ergonomic research developed during a thesis on temporal management in dynamic work situations. We present a temporal categorization based on different social science approaches. This categorization is operationalized through the analysis of middle-manager activity in horticultural production. We first specify the temporal requirements in terms of intertwined timeframes which these workers manage within a complex "temporal work environment". We then set out our methodology, based on interviews in nine French nurseries and horticultural sites and on systematic observation of five "chefs de culture" (middle managers in charge of horticultural production) during their activity. We analyze the different ways in which these workers consider the timeframes and deal with their temporal environment. The results have led us to suggest four complementary temporal concepts to understand multimodal temporal behaviour in dynamic situations. Our model thus distinguishes between: a "pushed by the past" time (1), a "pulled by the future" time (2), a "built by the present" time (3), and an uchronic time of "past alternatives" (4). These temporal conceptions are mobilized to analyze temporal configurations relating to work requirements, which lead to difficulties and risks that the "chefs de culture" treat, as part of their activity, as risks both for production and for workers' health.

\section{INDEX}

Mots-clés : gestion temporelle, cadres et milieu temporel, configurations temporelles, situations dynamiques, horticulture, risques professionnels

Keywords : activity-oriented ergonomics, temporal environment management, timeframes, temporal configurations, dynamic situations, horticulture, occupational risks 


\section{AUTEUR}

\section{VALÉRIE ZARA-MEYLAN}

Creapt, Centre d'Études de l'Emploi (CEE),

Le Descartes I - 29, promenade Michel Simon - 93166 Noisy-le-Grand

valerie.meylan@cee-recherche.fr 